\title{
Crash Analysis of a Conceptual Electric Vehicle with a Damage Tolerant Battery Pack
}

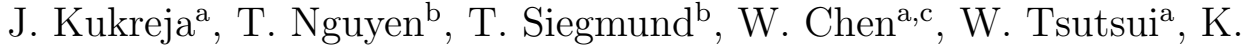 \\ Balakrishnan $^{a}$, H. Liao ${ }^{a}$, N. Parab ${ }^{a}$ \\ ${ }^{a}$ School of Aeronautics and Astronautics, Purdue University, 701 West Stadium Avenue, \\ West Lafayette, IN 47907, U.S.A. \\ ${ }^{b}$ School of Mechanical Engineering, Purdue University, 585 Purdue Mall, West \\ Lafayette, IN 47907, U.S.A. \\ ${ }^{c}$ School of Materials Engineering, Purdue University, 701 West Stadium Avenue, West \\ Lafayette, IN 47907, U.S.A.
}

\begin{abstract}
In current electric vehicles batteries fulfill only the role of power source and are stored within the passenger cabin, protected from external impact loads. This study considers a multifunctional, damage tolerant battery system which combines the energetic material with mechanically sacrificing elements that control mechanical stresses and dissipate energy. With such a multifunctional battery system in place it is proposed to place the battery pack into the secondary safe zone of a unibody-type vehicle. Full-vehicle crash analysis via finite element simulations are conducted for several battery pack configurations, thereby comparing the multifunctional battery system to battery packs with batteries alone and battery packs where cellular solids are used as energy absorbers. The analysis demonstrates the use of a multifunctional (damage tolerant and energy storage capable) battery system to ensure battery safety and aid in the energy absorption in a crash overall. The use of the multifunctional battery systems can aid in solving technology limitations of electric vehicles.

Keywords: battery, electric vehicle, energetic materials, multifunctionality, crash simulation, finite element analysis
\end{abstract}

Preprint submitted to Extreme Mechanics Letters

April 8, 2016

C) 2016. This manuscript version is made available under the Elsevier user license http://www.elsevier.com/open-access/userlicense/1.0/ 


\section{Introduction}

Electric vehicles $(\mathrm{EVs})$ provide propulsion using the energy stored in batteries on-board. Electric vehicles are understood to be highly efficient in converting stored electrical energy into mechanical energy. Yet, EVs also face several challenges associated with driving range, weight, and safety. Mutifunctional energy storage systems, addressing both energy storage and mechanical function are seen as necessary technological solutions in advancing EV and related technology [2]. Following [1] two directions of multifunctionality are relevant. In a combination electrical energy storage and load carrying capacity, multifunctional structural elements compose part of the primary and secondary vehicle structure. Relevant material and system level solutions have been demonstrated, e.g. [3, 4, 5, 6, 8, 7, 9, 10, 11]. Alternatively, a combination of electrical energy storage and mechanical impact mitigation capacity can be envisioned. Then, a multifunctional battery systems would contribute simultaneously to battery and vehicle safety. This direction of research has less been explored. In [12] a possible embodiment of a damage tolerant battery pack system was proposed whereby battery macrocells of trapezoidal shape (each composed of multiple cylindrical battery units) are combined with crash elements to absorb energy. In [13] a related concept is considered but without the additional requirement of packing individual battery units into macrocells. Thereby, individual cylindrical battery units are combined with tubes in a bimodal packing structure given by the diameters of battery units and tubes.

Safety under crash condition is a special concern for vehicles with alternative energy storage systems [14]. Based on consolidated data of real world accidents and laboratory crash tests for unibody-style vehicles [15], two safety zones are defined, Fig. 1. The passenger cabin is considered as the primary safe zone and is protected from external impact loads by an appropriately design vehicle structure. For most current electric vehicles, the primary safe zone is utilized for the placement of the battery pack. Since batteries are co-located with the passenger space and even if located in the primary safe zone, batteries require heavy protection against mechanical failure and consequences arising from failure. Furthermore, space in the passenger compartment is restricted and thus battery volume is limited, leading to constraints on EV range.

The present study investigates if battery packs could be located outside of 


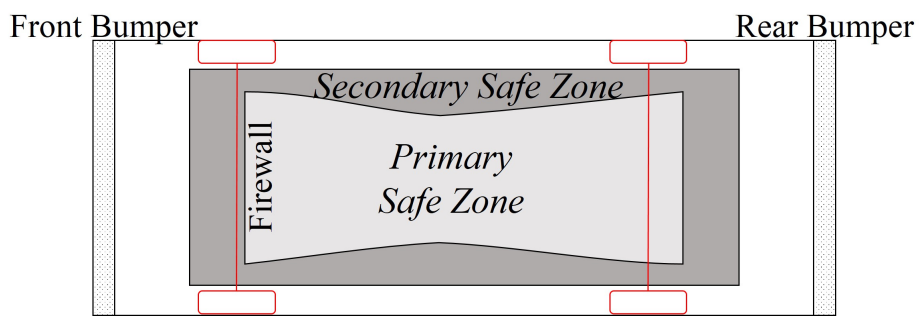

Figure 1: Safe zones in a vehicle based on data in [15] on vehicle intrusions in real world accidents and laboratory crash tests

the primary safe zone of a unibody-based EV. In particular, it is considered to place battery packs into the secondary safe zone. Then, the battery pack can no longer be considered as a rigid body since it will interact with the crumple zone of the vehicle. On the other hand, the battery pack will require appropriate protective mechanisms because the battery pack might experience failure under extreme conditions, such as a crash [14]. This study considers the multifunctional energy material system introduced in [13] which combines energy storage capacity with stress control and energy dissipation. The concept of the Granular Battery Assembly (GBA) is depicted in Fig. 2.

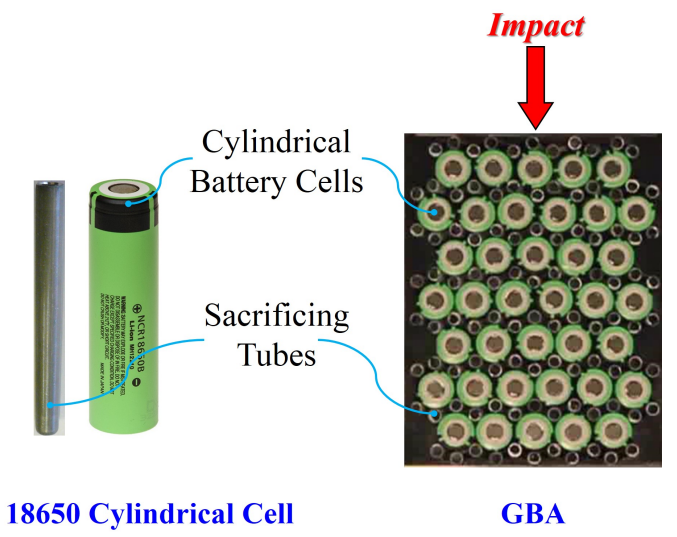

Figure 2: Granular Battery Assembly (GBA) as a combination of cylindrical battery units and sacrificing cellular unit elements.

GBA utilizes the cushion-in-advance principle [16] in the form of an embedded energy dissipation component. The plastic deformation of sacrificing tubes packed between the batteries limits the loads on batteries and dissi- 
pates energy. The overall mechanical response of GBA is similar to that of a cellular solid [13] exhibiting an initial elastic response, a plateau regime due to the tube collapse process, followed by a densification regime. GBA acts as a power source during normal operation of an EV. Under extreme mechanical loading during crash GBA simultaneously dissipates impact energy and limits stresses on the battery units.

When considering multifunctional material solutions, overall system performance is the goal but penalties can arise on individual functionalities. The present study investigates conceptual EV configurations under crash conditions to assess the degree of effectiveness of the GBA approach and the degree of the emerging penalties due to the use of GBA. 


\section{Methods}

A typical IC powered unibody-based sedan style vehicle was used as the starting point of the present study. The model corresponds to the structure of a 2012 Toyota Camry sedan (total vehicle mass $=1421 \mathrm{~kg}$ ). The model and the finite element discretization for this structure were obtained from the National Crash Analysis Center (NCAC) [17]. Finite element (FE) simulations of a full frontal barrier crash against a rigid impact wall for each of the vehicle configurations were used to evaluate the crash safety response. The crash simulations for this study were performed on LS-DYNA platform [18]. In the analysis the constitutive response of the steel components representing the vehicle frame follows the constitutive model of Cowper and Symonds [19]. The specific property data are those made available from NCAC [17] and correspond to the material properties used in the validated crash model. The crash response for the model was validated with the New Car Assessment Program (NCAP) Frontal Impact Test number 7520 (35 mph, 56 km/h) [20] and good overall agreement between experimental and simulation data was obtained.

In order to create electric vehicle configurations, a base vehicle frame was obtained by removal of the internal combustion (IC) components from the vehicle model. Four different EV configurations were investigated (Fig. 3). These configurations utilize the front compartment for battery pack storage and place battery packs in the secondary safe zone adjacent to the firewall but outside of the passenger cell. Additional batteries were also placed in the space of the original gas tank. This battery pack is in the primary safe zone. The remainder of the vehicle structure model was kept in its original definition.

For the calculation of ESC it was assumed that each battery cell (Panasonic 18650 [21]) can store $10.4 \mathrm{Wh}(214 \mathrm{Wh} / \mathrm{kg}$ and $577 \mathrm{Wh} / \mathrm{L})$. The case EV 1 considers a battery pack consisting of batteries only (Fig. 3(a)). The model considered a battery mass of $278.92 \mathrm{~kg}$ corresponding to 5940 battery cells and a energy storage capacity (ESC) of $61.78 \mathrm{kWh}$. For EV 2 (Fig. 3(b)), the battery pack is of identical volume of that in EV 1 but uses a GBA configuration. For a typical GBA configuration one can assume a tube diameter of $9.53 \mathrm{~mm}$ and tube wall thickness of $1.0 \mathrm{~mm}$, a battery diameter of $18.4 \mathrm{~mm}$, length of battery and tube as $65.2 \mathrm{~mm}$. Considering these geometric parameters for the sacrificial tubes, the packing density for batteries is thus reduced from $91 \%$ to $62 \%$ (for one set of values for battery and sacrificing tube di- 


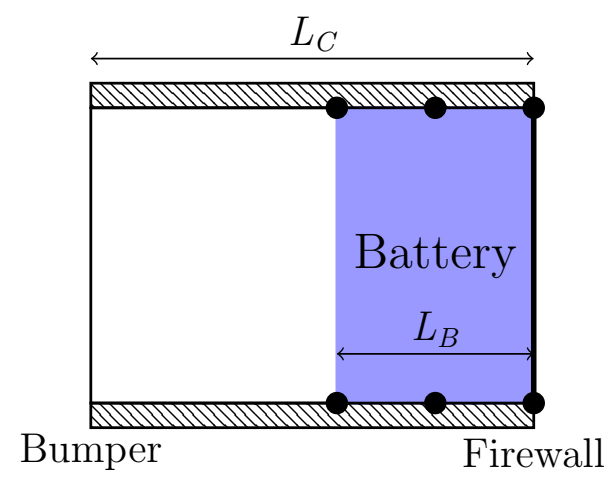

(a) EV 1: Batteries only

Mass $=278.92 \mathrm{~kg}$, Vol $=0.113223 \mathrm{~m}^{3}$;

$\mathrm{ESC} \cong 5940$ battery cells $\cong 61.78 \mathrm{kWh}$;

$221 \mathrm{Wh} / \mathrm{kg}, 546 \mathrm{Wh} / \mathrm{L}$

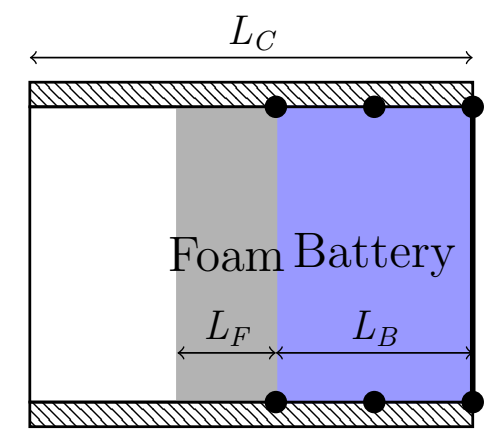

Bumper

Firewall

(c) EV 3: Battery (external protection) Mass $=333.27 \mathrm{~kg}, \mathrm{Vol}=0.166634 \mathrm{~m}^{3}$; $\mathrm{ESC} \cong 5940$ battery cells $\cong 61.78 \mathrm{kWh}$; $185 \mathrm{Wh} / \mathrm{kg}, 370 \mathrm{Wh} / \mathrm{L}$

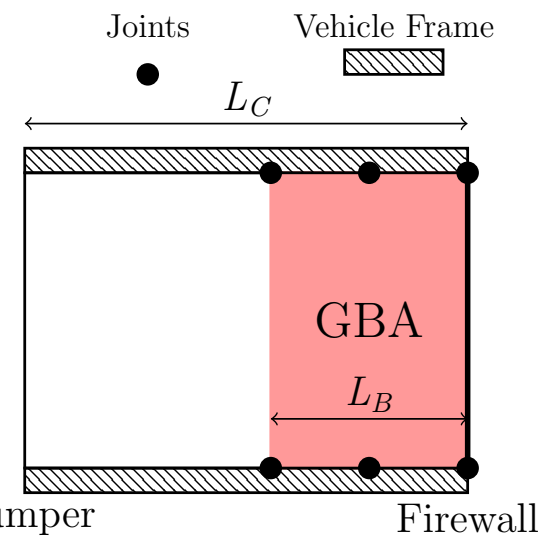

(b) EV 2: GBA (Embedded protection) Mass $=226.45 \mathrm{~kg}, \mathrm{Vol}=0.113223 \mathrm{~m}^{3}$; $\mathrm{ESC} \cong 4035$ battery cells $\cong 41.96 \mathrm{kWh}$; $185 \mathrm{Wh} / \mathrm{kg}, 370 \mathrm{Wh} / \mathrm{L}$

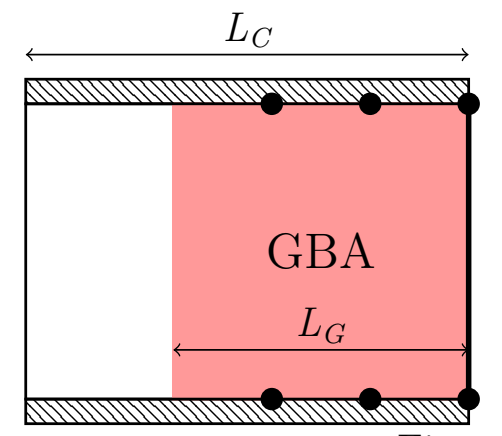

Bumper Firewall

(d) EV 4: GBA (embedded protection) Mass $=333.27 \mathrm{~kg}, \mathrm{Vol}=0.166634 \mathrm{~m}^{3}$; $\mathrm{ESC} \cong 5940$ battery cells $\cong 61.78 \mathrm{kWh}$; $185 \mathrm{Wh} / \mathrm{kg}, 370 \mathrm{Wh} / \mathrm{L}$

Figure 3: Schematic drawings representing the EV concepts in the secondary safe zone in the vehicle front compartment: (a) EV 1 - Battery only (no protection); (b) EV 2 - GBA (embedded protection) with ESC penalty; (c) EV 3 - Battery with external protection, with mass penalty; (d) GBA (embedded protection) with mass penalty. $L_{C}=705 \mathrm{~mm}$, $L_{B}=280 \mathrm{~mm}, L_{F}=140 \mathrm{~mm}, L_{G}=420 \mathrm{~mm} ; \mathrm{ESC}=$ energy storage capacity. mass and volume data refer to the battery pack overall.

mensions and packing configuration). This resulted in a $32 \%$ reduction in ESC relative to EV 1. The battery pack in EV 2 has a mass of $226.45 \mathrm{~kg}$, 
contains 4035 battery units and would store 41.96 kWh. For EV 3 (Fig. 3(c)) the battery pack used in EV 1 is now protected using an external foam. Considering battery pack and foam jointly, the combined mass is $19 \%$ increased relative to EV 1. EV3 and EV 1 possess the same ESC. EV 4 (Fig. 3(d)) uses the GBA configuration while keeping the same ESC as EV 1 and EV 3. EV 4 has the same volume, the same mass and ESC as EV 3, but the material distribution is different. For GBA (EV2 and EV4) compared to the battery-only pack in EV1 the gravimetric specific energy storage is reduced by $13 \%$ while the volumetric specific energy storage is reduced by $35 \%$.

The total mass of the vehicle used in the crash simulation included the mass for the base vehicle frame, the battery packs, and numerical masses added accounting for passengers and luggage. For example, for EV 1 the total mass is comprised of the vehicle structure $(1075 \mathrm{~kg})$, the battery pack in the front compartment's secondary safe zone $(279 \mathrm{~kg})$, the battery pack in the space of the original gas tank $(205 \mathrm{~kg})$ and an assumed mass for passengers and luggage $(207 \mathrm{~kg})$. Among the EV models only the mass for the battery pack in the front compartment was varied. For the IC-based model the vehicle model is comprised of the vehicle structure $(1075 \mathrm{~kg})$, the IC components $(350 \mathrm{~kg})$, and an assumed mass for passengers and luggage $(207 \mathrm{~kg})$. The IC vehicle possesses mass lower than all of the EV configurations.

The battery packs and the foam were discretized using 8-node solid brick elements of size $10 \mathrm{~mm}$. These model components were mounted onto the vehicle frame using numerical constraints on selected locations near the corners of the component domains (see e.g. Fig. 3(a)) which are close to structural members of the vehicle. The locations for these constraints were chosen such that they provide support to the block and prevent its rotational motion.

The mechanical response of the battery pack in EV 1 was approximated as a linear elastic material. This response approximates the response of batteries at stresses below failure well. The mechanical response of GBA battery pack (EV 2 and EV 4) was modeled by an equivalent foam material model (MAT063 [18] in LS-DYNA). This response consists of an initial elastic response, a plateau regime and a densification domain. The foam type response is the result of the collapse of the sacrificial tubes. Here, these tubes were assumed to be Al 6061-T6. Mechanical properties for the protective foam in EV 3 were derived by considering a metallic foam part of the same mass and volume as the aggregate of all sacrificial tubes in EV4. Based on the respective foam density an empirical relationship, Hou et al. [22] was used to obtain the mechanical properties of the foam. Table 1 shows the mechan- 
ical property values assigned to the different material models for the battery packs.

Table 1: Material properties for the battery packs

\begin{tabular}{cccc}
\hline & Battery & GBA & $\begin{array}{c}\text { Protective } \\
\text { foam }\end{array}$ \\
\hline $\begin{array}{c}\text { Material } \\
\text { model }\end{array}$ & $\begin{array}{c}\text { Elastic } \\
\text { (MAT001) }\end{array}$ & $\begin{array}{c}\text { Crushable foam } \\
\text { (MAT063) }\end{array}$ & $\begin{array}{c}\text { Crushable foam } \\
\text { (MAT063) }\end{array}$ \\
\hline $\begin{array}{c}\text { Density } \\
\left(\mathrm{kg} / \mathrm{m}^{3}\right)\end{array}$ & 2463.52 & 2000.00 & 1018.41 \\
\hline $\begin{array}{c}\text { Young's } \\
\text { modulus (MPa) }\end{array}$ & 2100 & 420 & 92.12 \\
\hline $\begin{array}{c}\text { Poisson's } \\
\text { ratio }\end{array}$ & 0.33 & 0.00 & 0.00 \\
\hline $\begin{array}{c}\text { Plateau } \\
\text { stress (MPa) }\end{array}$ & - & 3.00 & 63.40 \\
\hline $\begin{array}{c}\text { Densification } \\
\text { strain }\end{array}$ & - & $20 \%$ & $60 \%$ \\
\hline
\end{tabular}

Battery safety was investigated by examining the computed values of the maximum principle compressive stresses $\left(\sigma_{3}\right)$ within the battery packs. A representative failure stress $\left(\sigma_{f}=20 \mathrm{MPa}\right)$ was obtained using the compressive failure load determined from single battery cell experiments [13]. The allowable stress level $\left(\sigma_{\text {allow }}\right)$ was determined by employing a factor of safety (FS) with the failure stress level; $\sigma_{\text {allow }}=\sigma_{f} / \mathrm{FS}$. The number of failed elements in the battery pack was calculated by comparing the maximum principal compressive stresses for each element with the allowable stress level; if $\sigma_{3}^{\text {elem }} \geq \sigma_{\text {allow }}$ the element has failed. This failure criterion was selected since the load under crash is predominantly compressive.

The calculations for the total number of battery cells and the number of equivalent failed battery cells are given in Eq.(1). The total number of battery cells in the battery pack is given by:

$$
n_{b}=\frac{\text { Volume of the battery pack } \times \eta}{\text { Volume of one battery cell }}
$$

The percentage of failed battery elements in the battery pack is the number of failed battery elements to the total number of battery elements (denoted as $\alpha$ ), and : and the number of equivalent failed battery cells is given by $n_{f}=\alpha \times n_{b}$ where $\eta$ is the battery density for the battery pack (91\% for batteries; $62 \%$ for GBA).

In the absence of a human dummy in the FE model, passenger safety was estimated using surrogate measures. Computed data for the force response onto the rigid impact wall was used to calculate the Vehicle Acceleration 
Pulse (VAP). The time history of VAP was obtained by normalizing the wall force data with the total vehicle mass for each case. Head Injury Criterion (HIC) values were calculated using the acceleration data following standard procedure for the HIC criterion, [23]. The acceleration data used in the HIC assessment are those computed at the left rear floor position inside the passenger cabin. 


\section{Results and Discussion}

As one example of the computational simulations Fig. 4 shows snapshots from the crash simulation for EV 2. The undeformed configuration, Fig. 4(a), depicts the location of the battery pack (colored blue) in the FE model. At early stages of the crash processes, Fig. 4(b), the battery pack experiences little to no deformation and all impact is carried by the vehicle frame. Once the front crumple zone is compacted the bumper structure impacts the battery pack and imposes a dynamic load on the battery pack. This process is similar for all EV configurations considered here where an empty space (such as a front trunk found in current electric vehicle sedan models) is assumed to be present.

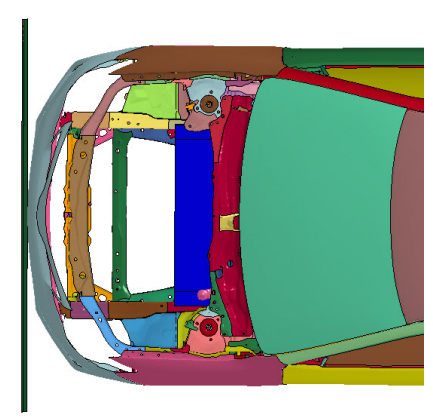

(a) $\mathrm{t}=0.00 \mathrm{~s}$

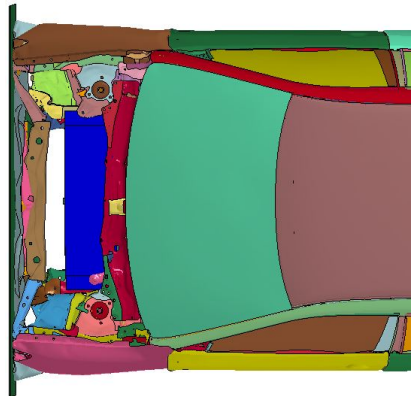

(b) $\mathrm{t}=0.04 \mathrm{~s}$

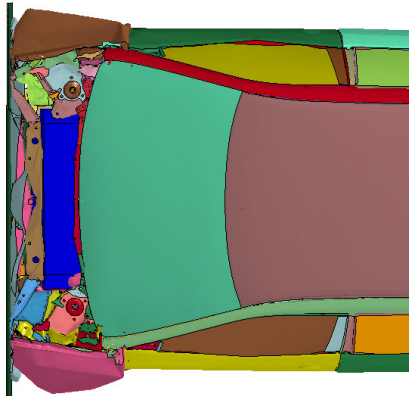

(c) $\mathrm{t}=0.08 \mathrm{~s}$

Figure 4: Snapshots from the full frontal crash simulation for EV 2. The battery pack is depicted in blue. (a) $t=0.00 \mathrm{~s}$; (b) $t=0.04 \mathrm{~s}$; (c) $t=0.08 \mathrm{~s}$

Computed VAP data are shown in Figure 5. The VAP record is similar for the four EV cases until around $t=0.035 \mathrm{~s}$. Up to this instance only the vehicle frame and structural members, which are identical for all the four cases, are experiencing impact loads. For all EV cases an initial high VAP occurs at $t=0.028 \mathrm{~s}$ with a subsequent drop in the VAP. After the battery pack comes in contact with the bumper structure, the resulting wall force is a combination of both the battery pack and the vehicle frame. The maximum peak VAPs occurs at $t=0.06 \mathrm{~s}$ for EV 1 and EV 2 , and at $t=0.05 \mathrm{~s}$ for EV 3 and EV 4. The differences in time to maximum VAP are the consequence of the spatial extension of the battery plus foam and the GBA battery pack in EV 3 and EV 4, respectively. In both cases the distance across the empty space in the front compartment is smaller than for EV 1 and EV 2. As a comparison, the VAP computed for the original IC-based vehicle model is 
given. In that case the $\mathrm{IC}$ components are spread out through the front compartment. As a consequence of the involvement of the IC components, the VAP rises early on $t=0.025 \mathrm{~s}$ and is computed to be larger than that for the EVs between $t=0.025 \mathrm{~s}$ and $t=0.04 \mathrm{~s}$. Overall the EV cases were predicted to possess lower maximum VAP values than the IC-based vehicle model. The legend in Figure 5 also shows the HIC values calculated for the four EV cases and the IC based vehicle model. The HIC values for all the four $\mathrm{EV}$ cases are found to be lower than the HIC value for the IC-based vehicle model. For EV 1 the battery pack deforms elastically only and the $\mathrm{HIC}$ value for this case is the larger than those for all other EV configurations. Including either the GBA approach or the external foam protection resulted in a $5 \%$ reduction of the $\mathrm{HIC}$ value relative to $\mathrm{EV} 1$.

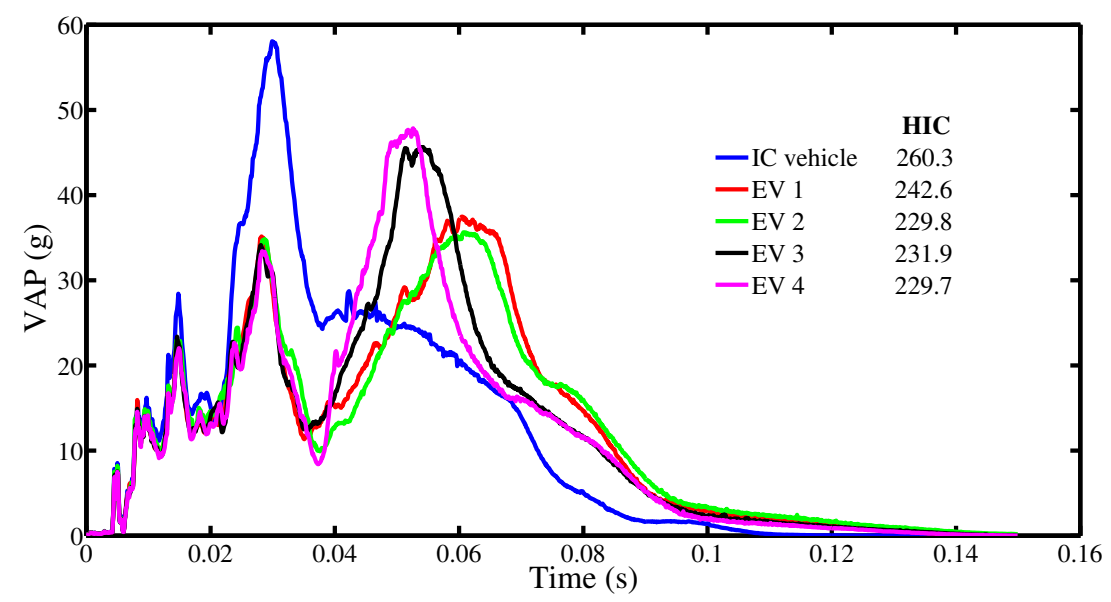

Figure 5: Vehicle acceleration pulse and HIC values computed for the four EV cases and IC vehicle

In order to assess the safety of batteries during the crash event, the $3^{\text {rd }}$ principal stress $\left(\sigma_{3}\right)$ contours for all EV cases are shown in Fig. 6 at the instance of the maximum VAP. In all cases high values of $\sigma_{3}$ occur at the corners of the battery packs. These locations are associated with the constraints to mount the battery pack to the vehicle frame, and the high $\sigma_{3}$ values result from inertial loads. In $\mathrm{EV} 1$ a domain of high $\sigma_{3}$ values mainly results from a bending mode of deformation of the battery pack. In EV 2 to EV 4, domains of high values of $\sigma_{3}$ are associated with the impact of the front bumper structure onto the battery pack and appear less to be a 


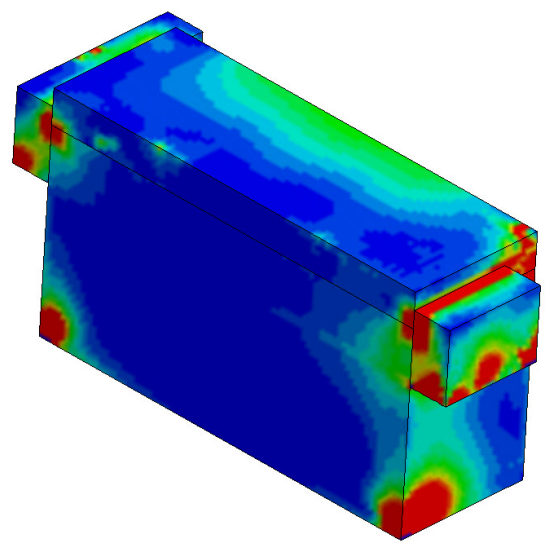

(a) EV 1 at $0.060 \mathrm{~s}$

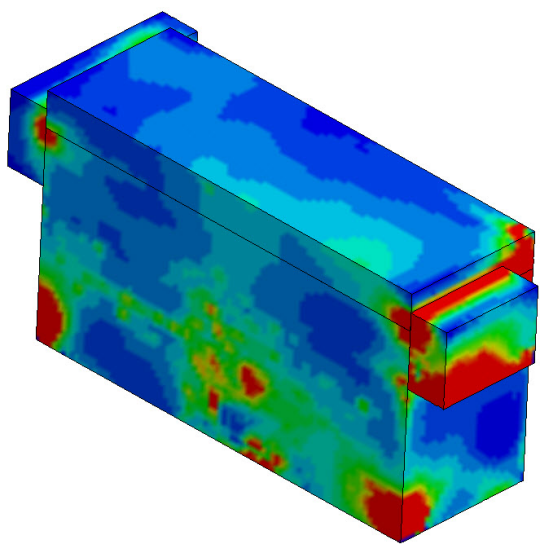

(c) EV 3 at $0.055 \mathrm{~s}$

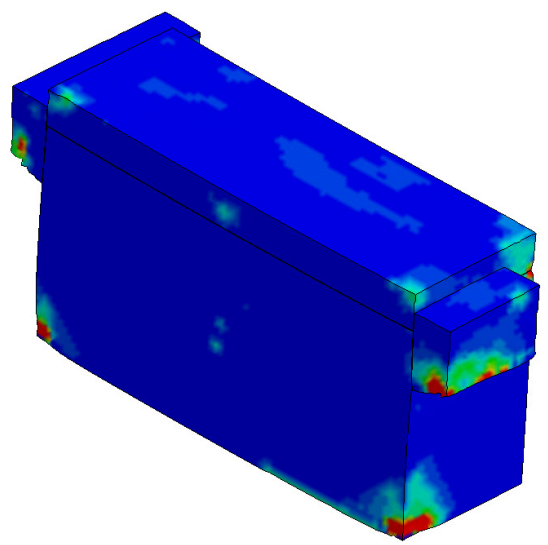

(b) EV 2 at $0.060 \mathrm{~s}$

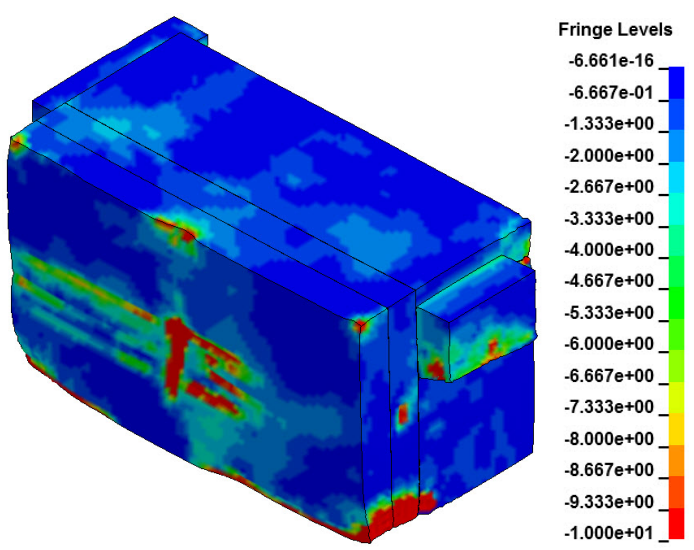

(d) EV 4 at $0.055 \mathrm{~s}$

Figure 6: Computed contours of the $3^{\text {rd }}$ principal stress for the battery pack at the instance of VAP: (a) EV 1; (b) EV2; (c) EV 3, (the battery domain only is shown); (d) EV 4 (the entire GBA domain is shown. Units of the contour values in $\mathrm{MPa}$

result of the interaction of the battery pack with the firewall. This process is least pronounced in EV 2 as the distance between bumper and battery pack is larger than in the other cases. The tube collapse mechanism and the reduced mass compared to EV 1, reduce the stresses considerable compared to EV 1. Considering EV 3, it is found that the use of the protective foam spreads the stresses in the battery pack over a wide space, while the impact of the bumper structure directly on the battery pack in EV 4 leads to more 
localized domains of high stresses.

A quantitative measure of predicted battery failure is obtained by comparing the computed stresses in the elements $\left(\sigma_{3}^{\text {elem }}\right)$ with the allowable stress $\left(\sigma_{\text {allow }}\right)$. Based on this criterion, the percentage failed elements in battery pack, and then the number of equivalent failed battery cells was computed. Factor of safety values of 1.0, 2.0, 3.0, and 7.0 were considered. Table 2 lists the respective data for all four EV cases and the assumed factors of safety. For the present simulations for EV 1, 1\% to $17 \%$ of the batteries were predicted to fail in the crash, depending on the FS used. Clearly, for EV 2 a substantial reduction of battery failure is found since EV 2 possesses a reduced battery mass, and employs the tube collapse mechanism. In EV 3, the use of the external foam to protect the battery pack leads to a reduction the level battery failure by a factor of 1.2 to 1.7 (depending on the FS used) relative to EV 1. In EV 4, the use of the GBA battery pack leads to a reduction in the level of battery failure by a factor of 2.6 to 3.9 (depending on the FS used) relative to EV $1 . \mathrm{EV} 3$ and EV 4 possess identical mass and energy storage capacity but employ two different concepts of protection (external vs. internal). It is found that the use of GBA in EV 4 leads to a reduction in the level of battery failure by a factor of 2.0 to 2.3 (depending on the FS used) relative to EV 3 where the external protective foam is used.

Table 2: Equivalent failed battery cells in the front compartment for four values of allowable stresses

\begin{tabular}{|c|c|c|c|c|c|}
\hline Case & $\begin{array}{c}\text { Allowable } \\
\text { Stress } \\
\text { (MPa) }\end{array}$ & $\begin{array}{l}\text { Time at peak } \\
\operatorname{VAP}(\mathrm{s})\end{array}$ & $\begin{array}{c}\text { Total Battery } \\
\text { Cells }\end{array}$ & $\begin{array}{c}\text { \% Failed } \\
\text { Battery } \\
\text { Elements }\end{array}$ & $\begin{array}{c}\text { Equivalent } \\
\text { Failed Battery } \\
\text { Cells }\end{array}$ \\
\hline \multirow{4}{*}{ EV 1} & 20 & \multirow{4}{*}{0.060} & \multirow{4}{*}{5940} & 1.05 & 63 \\
\hline & 10 & & & 2.48 & 148 \\
\hline & 7 & & & 4.02 & 239 \\
\hline & 3 & & & 17.09 & 1016 \\
\hline \multirow{4}{*}{ EV 2} & 20 & \multirow{4}{*}{0.060} & \multirow{4}{*}{4035} & 0.07 & 3 \\
\hline & 10 & & & 0.29 & 12 \\
\hline & 7 & & & 0.51 & 21 \\
\hline & 3 & & & 1.94 & 79 \\
\hline \multirow{4}{*}{ EV 3} & 20 & \multirow{4}{*}{0.055} & \multirow{4}{*}{5940} & 0.83 & 50 \\
\hline & 10 & & & 2.11 & 126 \\
\hline & 7 & & & 3.34 & 199 \\
\hline & 3 & & & 10.08 & 599 \\
\hline \multirow{4}{*}{ EV 4} & 20 & \multirow{4}{*}{0.055} & \multirow{4}{*}{5940} & 0.40 & 24 \\
\hline & 10 & & & 0.97 & 58 \\
\hline & 7 & & & 1.40 & 84 \\
\hline & 3 & & & 4.33 & 258 \\
\hline
\end{tabular}

In the course of the present study several simplifying assumptions were made. The mechanical stresses experienced by the battery pack at a local level are substantively dependent on the details of the mounting system. Here, 
only a simplified model mounting system was employed, i.e. the mounting points are rigid constraints. The mechanical response of the battery system was approximated as isotropic despite the transverse isotropic microstructure. Yet, since loading is unidirectional, it is expected that the use of an anisotropic constitutive model would alter the crash response little. Finally, battery units are assumed as linear elastic solids. Following data in [24] the actual response would be non-linear but not highly so. Also, the potential for energy dissipation in the batteries was not accounted for. If the energy dissipation capacity of battery cells is included in the computation, then the predicted HIC values would further be reduced. Yet, at the same time the concept of GBA aims to avoid the irreversible deformation of battery cells since such events would invariably be associated with electrical failure. While the present study focuses on the use of GBA in the secondary safety zone of a vehicle, there are no fundamental constraints against the use of GBA in the primary safety zone. Such an approach can be used to protect EVs agains ground impact [25]. 


\section{Conclusions}

The performance of a conceptual EV with a unibody construction under the extreme loading condition in a frontal crash event is studied. In contrast to most current EV concepts, battery packs are located outside of the primary safe zone (i.e. the passenger compartment). Instead, battery packs are located in front of the firewall in the frontal vehicle compartment. It is proposed that battery packs can potentially be located in this secondary safe zone of the vehicle if a damage tolerant battery pack is considered. Such a multifunctional battery pack is introduced as the Granular Battery Assembly (GBA), where cylindrical battery units and collapsable and sacrificial metal tubes are arranged in a bimodal packing distribution. GBA is multifunctional as it possesses energy storage, stress control and energy dissipation characteristics. From computational crash simulations it was found that the use of GBA is more effective to mitigate battery failure in a crash than the use of a metal foam of density equivalent to that of the metal tubes in the GBA. Furthermore, the simulations indicate that GBA not only is effective in protecting batteries from failure during crash but it was also found that the use of GBA lead to reduced values of the computed Head Injury Criterion compared to a case where the battery pack consists of batteries only.

Multifunctionality is commonly associated with a penalty. The penalties on the gravimetric and volumetric specific energy storage capacity for the battery pack alone are 13 and $35 \%$, respectively. However, the key penalty is the added mass to the overall vehicle system as this determines the vehicle rolling resistance. Comparing the EV with battery-only configuration and the EV with GBA configuration under identical energy storage capacity, the mass penalty to the vehicle overall is $3 \%$ and due to the mass of the added metal tubes. This penalty appears to be small compared to an at least 2.6 fold reduction in batter failure level and a $5 \%$ reduction in HIC value. The volume penalty between the two configurations is more substantial. However, the battery only pack as well as the GBA pack only account for a minor fraction of the volume available between firewall and bumper. Consequently, at a system level the volume penalty appears as a minor concern.

The proposed approach of employing GBA to place battery packs in the secondary safe zone of a unibody based EV has two main consequences. The approach would decouple the battery pack space from the passenger compartment, thereby offering not only increased space for the battery pack itself, but also removing constraints in the vehicle design itself, and provid- 
ing a potential for increased space for passenger comfort and luggage storage. Furthermore, GBA contributes to lightweighting efforts for EVs in two ways. The damage tolerance of GBA would reduce the need for heavy protective structures for the battery pack and advance the use of unibody-style EVs, and the energy absorption capacity of GBA would contribute to a reduction of amount of material needed in the crumple of the vehicle. For a translation of the present simulation results into full vehicle applications manufacturing methods for GBA battery packs, a refinement of the GBA approach to include cooling and electrical connection aspects, as well as full experimental validation of the approach is needed.

The present study demonstrates that mechanics - through the analysis of the multifunctional energy material and the energy system overall - plays an important role in advancing electric vehicle technologies. 


\section{Acknowledgments}

This research was supported by the U.S. Department of Energy, Advanced Research Projects Agency - Energy, under contract no. DE-AR0000378.

T. Siegmund also acknowledges support from the National Science Foundation (N.S.F.) while working at N.S.F.

We would like to acknowledge the finite element model for a 2012 Toyota Camry Sedan. This model has been developed by The National Crash Analysis Center (NCAC) of The George Washington University under a contract with the FHWA and NHTSA of the US DOT. 
[1] P. Liu, R. Ross, A. Newman, Long-range, low-cost electric vehicles enabled by robust energy storage. MRS Energy \& Sustainability 2 (2015) E12.

[2] J. P. Thomas, M. A. Qidwai. The design and application of multifunctional structure-battery materials systems, JOM 57 (2005) 18-24.

[3] J.P. Thomas, M.A. Qidwai MA. Mechanical design and performance of composite multifunctional materials. Acta Mater. 82 (2004) May 21552164 .

[4] J.F. Snyder, R.H. Carter, E.D. Wetzel. Electrochemical and mechanical behavior in mechanically robust solid polymer electrolytes for use in multifunctional structural batteries. Chem. Mater. 19 (2007) 37933801.

[5] P. Liu, E. Sherman, A. Jacobsen. Design and fabrication of multifunctional structural batteries. J. Power Sources 189 (2009) 646-650.

[6] J.P. Thomas, M.A. Qidwai, W.R. Pogue III, G.T. Pham. Multifunctional structure-battery composites for marine systems. J. Compos. Mater. 47 (2013) 5-26.

[7] L.E. Asp, E.S. Greenhalgh. Structural power composites. Compos. Sci. Technol. 101 (2014) 41-61.

[8] S.M. Shalouf, J. Zhang, C.H. Wang. Effects of mechanical deformation on electric performance of rechargeable batteries embedded in load carrying composite structures. Plast. Rubber Compos. 43(2014) 98-104.

[9] E.S. Greenhalgh, J. Ankersen, L.E. Asp, A. Bismarck, Q.P Fontana, M. Houlle, G. Kalinka, A. Kucernak, M. Mistry, S. Nguyen, H. Qian. Mechanical, electrical and microstructural characterisation of multifunctional structural power composites. J. Compos. Mater. 49 (2015) 18231834 .

[10] D.J. OBrien, D.M. Baechle, O.B. Yurchak, E.D. Wetzel. Effect of processing conditions and electrode characteristics on the electrical properties of structural composite capacitors. Compos. Part A-Appl. S.68 (2015) 47-55. 
[11] A. K. Singh, L. Cao, J. Ma, J. Seo, C. E. Bakis, Y. Zhang, M. A. Hickner, C. D. Rahn. Design, manufacture and test of a novel structural battery based on sandwich construction, J. of Sandw. Struct. and Mater. 17 (2015) 666-690.

[12] C. Bouvy, S. Ginsberg, P. Jeck, B. Hartmann, S. Baltzer, L. Eckstein. Holistic battery pack design. in Proc. 21st Aachen Colloqium Automobile and Engine Technology (2012) 367 - 380.

[13] W. Tsutsui, T. Nguyen, H. Liao, N. Parab, J. Kukreja, T. Siegmund, W. Chen. Mechanical energy dissipation in a multifunctional battery system, MRS Advances (2016) 1-8.

[14] L. Hollmotz, M. Hackmann. Lithium ion batteries for hybrid and electric vehicles - risks, requirements and solutions out of the crash safety point of view, in Proc. 22nd Int. Techn. Conf. Enhanced Safety of Vehicles (ESV) (2011) no. 11-0269.

[15] J. Bakker, C. Sachs, D. Otte, R. Justen, L. Hannawald, F. Friesen. Analysis of fuel cell vehicles equipped with compressed hydrogen storage systems from a road accident safety perspective, SAE Int. J. Passeng. Cars Mech. Syst. 4 (2011) 332-342.

[16] K. Rantanen, E. Domb. Simplified TRIZ: New problem solving applications for engineers and manufacturing professionals, CRC Press, (2010).

[17] National Crash Analysis Center - Finite Element Model Archive, URL: http://www.ncac.gwu.edu/vml/models.html (last accessed: 02.15.2016).

[18] LS-DYNA Keyword User's Manual (Version 971) - Volumes I and II, URL: http://www.lstc.com/pdf/ls-dyna_971_manual_k.pdf (last accessed: 02.15.2016).

[19] G. R. Cowper, P. S. Symonds, Strain-hardening and strain-rate effects in the impact loading of cantilever beams, Tech. Rep., Brown University (1957).

[20] 2012 Toyota Camry 4 DR FWD | Safercar - NHTSA, URL: http://www . safercar.gov/Vehicle+Shoppers/5-Star+Safety+ 
Ratings/2011-Newer+Vehicles/Vehicle-Detail?vehicleId=6270

(last accessed: 02.15.2016).

[21] Panasonic Industrial Devices, URL: https://na.industrial. panasonic.com (last accessed: 02.15.2016).

[22] S. Hou, Q. Li, S. Long, X. Yang, W. Li, Crashworthiness design for foam filled thin-wall structures, Mater. Des. 30 (2009) 2024-2032.

[23] J. Hutchinson, M. J. Kaiser, H. M. Lankarani, The head injury criterion (HIC) functional, Appl. Math. Comput. 96 (1998) 1-16.

[24] T. Wierzbicki, E. Sahraei. Homogenized mechanical properties for the jellyroll of cylindrical Lithium-ion cells. J. Power Sourc. 241 (2013) 467476.

[25] Y. Xia, T. Wierzbicki, E. Sahraei, X. Zhang X. Damage of cells and battery packs due to ground impact. J. Power Sourc. 267 (2014) 78-97. 